\title{
Knowledge and Practice Regarding Menstrual Health among Physically Disabled Women in Kathmandu, Nepal
}

\author{
Bishal Pokhrel ${ }^{1}$, Sunita Mahat ${ }^{2}$, Kriti Parajuli ${ }^{3}$, Nishant Lama ${ }^{1}$ \\ ${ }^{1}$ Assistant Professor, Department of Community Medicine and Public Health, Karnali Academy of Health \\ Sciences, Jumla, Nepal. \\ ${ }^{2}$ Public Health Graduate, National Academy for Medical Sciences, Purbanchal University, Kathmandu, \\ ${ }^{3}$ Nutritionist, Padma Kanya Multiple Campus, Kathmandu, Nepal
}

Corresponding Author: Dr. Bishal Pokhrel; Email: dr.bishalpokhrel@gmail.com

\begin{abstract}
Background: Disability is the condition of difficulty in carrying out daily activities normally and in taking part in social life due to problems in parts of the body and the physical system as well as obstacles created by physical, social, cultural environment and by communication. Disability also carries stigma, so disabled people may face layers of discrimination when they are menstruating. The objective of the research is to assess the knowledge and practice regarding menstrual health of disabled women.

Method: Descriptive, cross sectional study was conducted among 151 participations. Self-structured questionnaire and face-to-face interview were used as data collection tool and technique respectively. Data entry and analysis were done using SPSS version 20. Descriptive analysis like frequency and percentages were computed and presented in a table.

Results: Most of participants knew 26-30 days were the normal menstrual cycle duration (80.13\%). Only 31\% of participants bath daily during menstruation. About $83 \%$ of participants used sanitary pad, $69.54 \%$ of participants changed pad twice a day. Maximum number (91.39\%) disposed sanitary pad in dustbin. $76.82 \%$ of participants learned about menstrual hygiene from parents and friends. Majority of the participants (61.59\%), cleaned the genitalia haphazardly 88.08\% cleaned with soap and water Most of the respondent $90.06 \%$ had taken rest during menstruation.

Conclusions: Disabled women were aware about normal duration of menstrual cycle and blood loss. However, improper practices related to menstrual health and hygiene were prevalent among disabled women, it should be timely and rightly approached to prevent and control adverse health conditions that may arise of it. Mother and peer groups could be the best choices of source of information to improve menstrual health and hygiene of differently able women.
\end{abstract}

Keyword: Knowledge, practice, menstrual hygiene and physically disabled

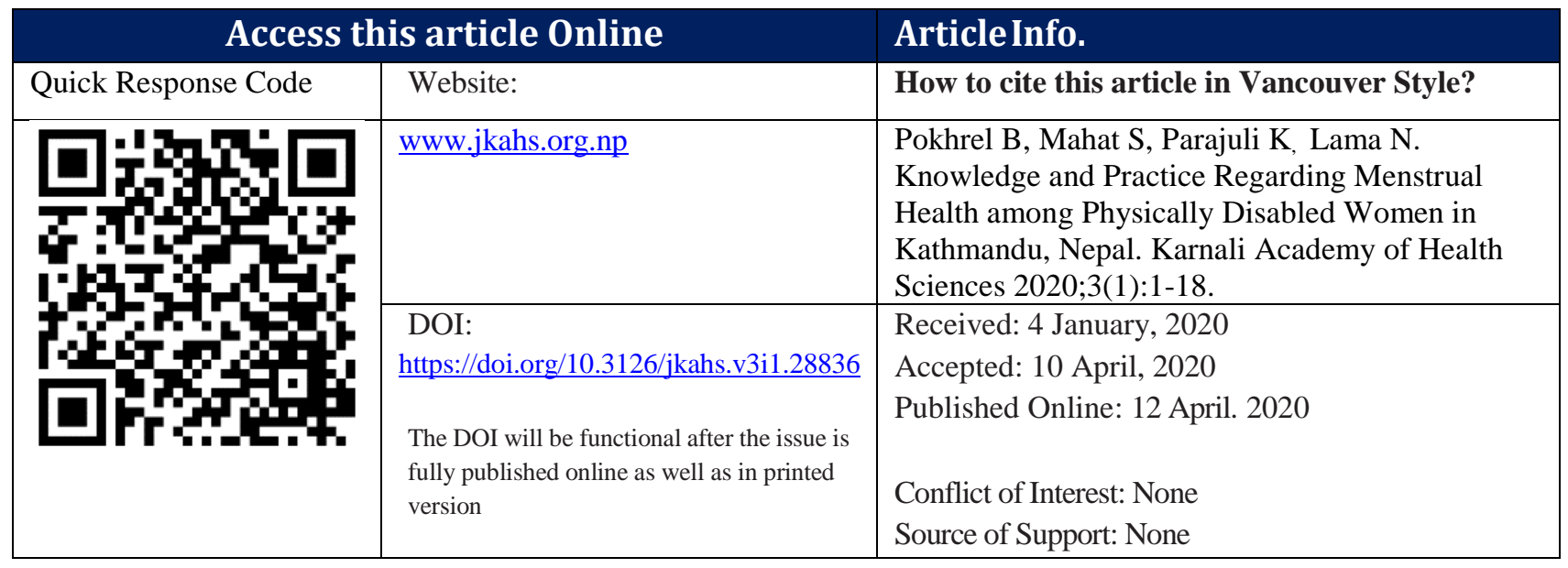




\section{INTRODUCTION}

"Disability is the condition of difficulty in carrying out daily activities normally and in taking part in social life due to problems in parts of the body and the physical system as well as obstacles created by physical, social, cultural environment and by communication”. ${ }^{1}$ Prevailing illiteracy, ignorance, and negative perception on the disability in the society is considered as the punishment of the god for some sin committed in the past life but it is not so. It is a human reality that occurs in all the ages from birth to old age. ${ }^{2}$

The onset of menstruation is the vital physiological change that occurred in girls during adolescence which is associated with the excessive intake of Junk/Fast Food. ${ }^{3}$ The prevailing taboos and socio-cultural prohibitions during menstruation are the determinants of adolescent girls being ignorant of scientific knowledge and practices regarding health and hygiene that are causing them to be the victim of adverse health outcomes. $^{4,5}$ Unhygienic menstrual practices may affect women's health causing vulnerability to RTI, PIDs and other complications. ${ }^{6}$ So, hygiene related practices of women during menstruation are crucial to health ${ }^{7}$.

According to population census 2011, nearly 2 $\%$ of total population of Nepal are disabled and among them $44 \%$ of them are female. Among these disabled female, $36 \%$ are physically disabled. $^{5}$

Obstetrician-gynecologists

encounter adolescents with disabilities in their practice. Teenagers with disabilities and their families my face complications in reproductive health issues like puberty, sexuality, and menstruation because of the concerns related to menstrual hygiene, risk of abuse and vulnerability to altered mood. ${ }^{5}$

In this condition menstruation and disability both are affected by socio-cultural factors. Thus our study will help to find out how disable women are vulnerable to menstrual health problems because of their knowledge and practices.

\section{MATERIALS AND METHODS}

The descriptive, cross sectional study was conducted to assess the knowledge and practice regarding menstruation health among physically disables women in Disable Rehabilitation Center, Jorpati area of Kathmandu. Sample size was calculated by using the formula $(\mathrm{n})=\frac{Z^{2} \mathrm{P}(1-\mathrm{P})}{d^{2}}$. Where, $\mathrm{n}=$ sample size, $\mathrm{P}=$ expected prevalence or proportion, $d=$ allowable error, $\mathrm{Z}=\mathrm{Z}$ statistic for a level of confidence. Putting $\mathrm{p}=0.89$ (Prevalence of knowledge regarding menstruation $)^{7}, d=5 \%=0.05, Z=1.96$ for $95 \%$ confidence interval, $1-\mathrm{p}=0.11$ in formula the required sample size was 151. Purposive sampling technique was used to select the required sample. The study was conducted from 15 Feb to 15 March 2018. Semistructured questionnaire was the tool and face 
to face interview was the technique to collect the data. The collected data was entered and analyzed in Statistical Package for Social Science (SPSS) version 20. Descriptive analysis like frequency and percentages were computed and presented in a table.

Ethical principles were followed taking written consent from each participant and maintaining confidentiality by using an appropriate code for the identity of each participant.

\section{RESULTS}

It was found that more than half of the participants (56.29\%) were of age group 15-24 years. Majority of the participants i.e. 94.03\% were found to be unmarried. Nearly 74\% participants followed Hindu religion. Majority of the participants were Brahmin (31.12\%) followed Janajati(23.18\%). Regarding educational status, $13.24 \%$ of the participants had achieved secondary, 37.09\% primary, 5.30\% Higher Secondary while $27.81 \%$ were literate and $16.56 \%$ were illiterate. More than one third of participants (38.41\%) had disability related to lower limb, 30.46\% had upper and lower limb related disability, and 22.52\% had Upper limb disability. (Table: 1.)
Table 1: Socio-demographic Characteristics of the Participants n=151

\begin{tabular}{|c|c|c|}
\hline $\begin{array}{l}\text { Socio-demographic } \\
\text { characteristics }\end{array}$ & Frequency $(n=151)$ & Percentage (\%) \\
\hline \multicolumn{3}{|l|}{ Age (In Years) } \\
\hline $15-24$ & 85 & 56.29 \\
\hline $25-34$ & 43 & 28.48 \\
\hline$>34$ & 23 & 15.23 \\
\hline \multicolumn{3}{|l|}{ Marital status } \\
\hline Unmarried & 142 & 94.03 \\
\hline Married & 9 & 5.97 \\
\hline \multicolumn{3}{|l|}{ Religion } \\
\hline Hindu & 112 & 74.17 \\
\hline Buddhist & 25 & 16.56 \\
\hline Christain & 14 & 9.27 \\
\hline \multicolumn{3}{|l|}{ Ethnicity } \\
\hline Bhramin & 47 & 31.12 \\
\hline Janajati & 35 & 23.18 \\
\hline Chettri & 43 & 28.48 \\
\hline Dalit & 22 & 14.58 \\
\hline Other & 4 & 2.64 \\
\hline \multicolumn{3}{|l|}{ Educational status } \\
\hline Illiterate & 25 & 16.56 \\
\hline Literate & 42 & 27.81 \\
\hline Primary & 56 & 37.09 \\
\hline Secondary & 20 & 13.24 \\
\hline Higher Secondary & 8 & 5.30 \\
\hline \multicolumn{3}{|l|}{ Type of disability } \\
\hline Lower limb & 58 & 38.41 \\
\hline Head neck spinal & 13 & 8.61 \\
\hline Upper and lower & 46 & 30.46 \\
\hline Upper limb & 34 & 22.52 \\
\hline
\end{tabular}

The $91.39 \%$ of participants reported the right age of menarche. About $80 \%$ of participants reported 26-30 days as normal menstrual cycle duration. Only 3.31\% of participants had taken health education class or training related to menstrual hygiene. It was found that $76.82 \%$ of participants were informed about menstruation by their parents, $10.61 \%$ by 
friends whereas other sources of information were by teachers and course book. (Table: 2.)

Table 2: Knowledge Regarding Menstruation (n=151)

\begin{tabular}{|c|c|c|}
\hline $\begin{array}{ll}\text { Knowledge } & \text { Regarding } \\
\text { Menstruation } & \end{array}$ & $\begin{array}{l}\text { Frequency } \\
(\mathrm{n}=151)\end{array}$ & $\begin{array}{l}\text { Percentage } \\
(\%)\end{array}$ \\
\hline \multicolumn{3}{|l|}{ Normal age of menarche } \\
\hline $11-15$ years & 138 & 91.39 \\
\hline Others & 13 & 8.61 \\
\hline \multicolumn{3}{|l|}{ Normal flow of bleeding } \\
\hline $3-5 \mathrm{ml}$ & 102 & 67.55 \\
\hline $5-7 \mathrm{ml}$ & 49 & 32.45 \\
\hline \multicolumn{3}{|c|}{ Normal menstrual cycle duration } \\
\hline 26-30 days & 121 & 80.13 \\
\hline $30-35$ & 26 & 17.22 \\
\hline Others & 4 & 2.65 \\
\hline \multicolumn{3}{|c|}{ Taken training/health education class } \\
\hline No & 146 & 96.69 \\
\hline Yes & 5 & 3.31 \\
\hline \multicolumn{3}{|c|}{ Source of knowledge about menstruation } \\
\hline Parents (mother) & 116 & 76.82 \\
\hline Friends & 16 & 10.61 \\
\hline Teachers & 13 & 8.60 \\
\hline Course book & 6 & 3.97 \\
\hline
\end{tabular}

Maximum number of participants (96.69\%) reported that they stayed at same place during menstruation. Also, $17 \%$ of participants reported that they bath daily during menstrual period. Maximum number of participants (98.01\%) reported that they ate food at same place. It was found that, $83.44 \%$ of participants used sanitary pad and $69.54 \%$ of participants changed pad twice a day. Among the participants, 99.34\% did not share common pads and 96.69\% did not reuse pad at all. Regarding disposal of pads, $91.39 \%$ of participants disposed pad in dustbin, 5.30\% in separate place and $3.31 \%$ buried in mud. Among the participants, $61.59 \%$ clean genitilia haphazardly while $35.10 \%$ anterior to posterior and $3.31 \%$ posterior to anterior. Most of the participants (88.08\%) used soap and water to clean genitilia. Maximum number of participants reported that they take rest during menstruation (Table: 3.)

Table 3: Practice Regarding Menstrual Health $n=151$

\begin{tabular}{|c|c|c|}
\hline $\begin{array}{l}\text { Practice Regarding } \\
\text { Menstrual Health }\end{array}$ & $\begin{array}{l}\text { Frequency } \\
(n=151)\end{array}$ & $\begin{array}{l}\text { Percentage } \\
(\%)\end{array}$ \\
\hline \multicolumn{3}{|l|}{ Stay during period } \\
\hline Same place & 146 & 96.69 \\
\hline Separate place & 5 & 3.31 \\
\hline \multicolumn{3}{|l|}{ Time of bath } \\
\hline 1st day & 26 & 17.22 \\
\hline 4th day & 65 & 43.05 \\
\hline Daily & 48 & 31.79 \\
\hline Others & 12 & 7.94 \\
\hline \multicolumn{3}{|l|}{ Place to eat food } \\
\hline Same place & 148 & 98.01 \\
\hline Outside kitchen & 3 & 1.99 \\
\hline \multicolumn{3}{|l|}{ Type of pad } \\
\hline Clothes & 25 & 16.56 \\
\hline Sanitary pad & 126 & 83.44 \\
\hline \multicolumn{3}{|l|}{ Period to change pad } \\
\hline Change daily & 16 & 10.60 \\
\hline Twice a day & 105 & 69.54 \\
\hline Depends upon situation & 30 & 19.86 \\
\hline \multicolumn{3}{|l|}{ Share common pads } \\
\hline No & 150 & 99.34 \\
\hline Yes & 1 & 0.66 \\
\hline \multicolumn{3}{|l|}{ Reuse pad } \\
\hline No & 146 & 96.69 \\
\hline Yes & 5 & 3.31 \\
\hline \multicolumn{3}{|l|}{ Place of pad disposal } \\
\hline Buried in Mud & 5 & 3.31 \\
\hline Dustbin & 138 & 91.39 \\
\hline Separate place & 8 & 5.30 \\
\hline \multicolumn{3}{|c|}{ Technique to clean genitilia } \\
\hline Anterior to posterior & 53 & 35.10 \\
\hline Posterior to anterior & 5 & 3.31 \\
\hline Haphazardly & 93 & 61.59 \\
\hline \multicolumn{3}{|l|}{ Cleaning genitilia with } \\
\hline Soap and water & 133 & 88.08 \\
\hline Plane water & 18 & 11.92 \\
\hline \multicolumn{3}{|c|}{ Take rest during menstruation } \\
\hline No & 15 & 9.93 \\
\hline Yes & 136 & 90.06 \\
\hline
\end{tabular}


About $82 \%$ of disable women faced common problems during menstruation. Among them 44.80\% faced dysmenorrhea, abnormal blood flow (22.40\%) and premenstrual symptom (32.80\%). To cope with common problems reported above, $44.80 \%$ took rest, $17.60 \%$ used hot water bag, $22.40 \%$ ate food, and $15.20 \%$ of them took medicine. (Table: 4.)

Table 4: Common Problems and Coping Strategies during Menstruation ( $n=151)$

\begin{tabular}{|c|c|c|}
\hline $\begin{array}{l}\text { Health related } \\
\text { information }\end{array}$ & Frequency $(\mathrm{n}=151)$ & $\begin{array}{l}\text { Percentage } \\
(\%)\end{array}$ \\
\hline \multicolumn{3}{|c|}{ Faced Common Problem During Period } \\
\hline No & 26 & 17.21 \\
\hline Yes & 125 & 82.79 \\
\hline \multicolumn{3}{|c|}{ Common problems $(n=125)$} \\
\hline Dysmenorrhea & 56 & 44.80 \\
\hline $\begin{array}{l}\text { Abnormal blood } \\
\text { flow }\end{array}$ & 28 & 22.40 \\
\hline $\begin{array}{l}\text { Premenstrual } \\
\text { symptom }\end{array}$ & 41 & 32.80 \\
\hline \multicolumn{3}{|c|}{ Coping strategy $(n=125)$} \\
\hline Medicine & 19 & 15.20 \\
\hline Food & 28 & 22.40 \\
\hline Hot water bag & 22 & 17.60 \\
\hline Rest & 56 & 45.80 \\
\hline
\end{tabular}

\section{DISCUSSION}

The study showed that $56.29 \%$ of participants were of age group 15 -24 while $28.48 \%$ of 25 34 and $15.23 \%$ were above 34 years. Majority of the participants i.e. $94.03 \%$ were found to be unmarried. Majority of the participants were Brahmin (31.12\%) followed by Chrettri (28.48\%). Regarding educational status, $13.24 \%$ of the participants had achieved secondary, 37.09\% primary, 5.30\% Higher Secondary while $27.81 \%$ were literate and $16.56 \%$ were illiterate. The study conducted in Chitwan district of Nepal and North India also shows similar age group of menstrual cycle as well as education level. ${ }^{6,12}$ Maximum number of participants (38.41\%) had disability related to lower limb. The study done in rural Nepal also revealed that limb disability was the most common one. ${ }^{13}$

In the present study the most common source of information to disabled women about menstruation health and hygiene were their mothers. This is supported by the study done in West Bengal. ${ }^{3}$ However, the study done in rural Nepal (only 2.6\% from parents) contrast to the result of our study. ${ }^{11-13}$ Dysmenorrhea was the commonest problem faced during menstruation (44.80\%) followed by premenstrual symptom and abnormal blood flow. Maximum number of participants (83.44\%) used sanitary pads and frequency of changing pads twice a day was highest. Similar studies conducted in India and Nepal also shows same results. ${ }^{7,9,14}$

In this study, maximum number of participants (45.80\%) reported that they take rest during menstruation to cope with menstrual problem. The study done in Thailand also showed that taking rest was the most common coping measures during menstrual problems. ${ }^{15}$

The sanitary pads were used by $83.44 \%$ of disabled women and $69.54 \%$ used to change pad twice a day which was similar to other studies., ${ }^{72}$ Only $3.31 \%$ of participants had 
taken health education class or training related to menstrual hygiene which resembled with the study done in rural community in Northern India. ${ }^{6}$

Among the participants, $61.59 \%$ clean genitilia haphazardly while $35.10 \%$ anterior to posterior and 3.31\% Posterior to anterior. In our study, most of the participants (88.08\%) used soap and water to clean genitilia. Out of 160 participants of Uttarkhand, India, for cleaning purpose, $97.5 \%$ girls used both soap and water. ${ }^{6}$ However, Unicef guidance on Menstrual Health and Hygiene revealed that cleaning genitilia anterior to posterior is the correct technique and cleaning genitilia with clean water is the correct practice. ${ }^{12}$ About $43 \%$ of disabled women take bath at $4^{\text {th }}$ day of menstruation followed by $31.79 \%$ daily. However, Egyptian women take shower regularly during menstruation. ${ }^{16}$

Limitations: The study was conducted in Disable Rehabilitation Center, Jorpati area of Kathmandu with 151 physically disabled women; therefore, result of the study cannot be generalized for all women. The result revealed was for the study period only because it was a cross sectional study.

\section{CONCLUSION}

Large proportion of disabled women were aware about the duration of normal. menstrual cycle and amount of normal blood loss. Majority of them have improper menstrual health and hygiene practices such as bathing only in fourth day of menstruation, cleaning genitilia with soap and. water, and using wrong cleaning technique. Since, mothers and friends were the best sources of information about menstrual health and hygiene to disabled women, government and concerned organizations should provide health education through educating mothers as well as peer groups.

Acknowledgements: Authors express heartfelt thanks to rehabilitation centers (Disability New life Center, National Disability Women Association, National Disabled Association, Disable Rehabilitation center, Khagendra Disable School, Jorpati, Kathmandu). We also extend gratitude and appreciation to all participants of this study.

\section{REFERENCES}

1. Definition and classification of disability in Nepal. Government of Nepal; 2006. Full Text

2. Sharma J. A Study on the Social Status of Women with Disabilities.2007. PubMed

3. Amgain K, Neupane S. Effects of Food Habits on Menstrual Cycle among Adolescent Girls . Europasian J. of Med. Sci. [Internet]. 2020Mar.12 [cited 2020May13];1(1):53-1. Google Scholar | Full Text

4. Dasgupta S. Menstrual Hygiene: How Hygienic is the Adolescent Girl? Indian J Community Med. 2008;33(2):77-80. Google Scholar | PubMed | Crossref

5. People with Disability: Central Bureau of Statistics; 2011. PubMed 
6. Arbor A. Menstrual and reproductive issues in adolescents with physical and developmental disabilities. 2014;124(2):367-75. Google Scholar $\mid$ PubMed | Crossref

7. Misra P UR, Sharma V, Anand K, Gupta V. A community-based study of menstrual hygiene practices and willingness to pay for sanitary napkins among women of a rural community in northern India. The National Medical Journal of India. 2013;26(6):335-7. Google Scholar | Full Text

8. Thakur H, AA. et al. Knowledge, Practices, and Restrictions Related to Menstruation among Young Women from Low Socioeconomic Community in Mumbai, India., 2014. Google Scholar | Full Text

9. Sapkota D, SD, Budhathoki SS, Khanal VK, Pokharel HP. Knowledge and practices regarding menstruation among school going adolescents of rural Nepal. 2013;2(5):117-21.

Google Scholar | CrossRef

10. Rupa Vani K, Bupathy A. Menstrual Abnormalities in School Going Girls Are They Related to Dietary and Exercise Pattern?. Journal of Clinical and Diagnostic Research. 2013; November:7(11). Google Scholar | Full Text

11. Kamath R GD, Lena A, Chandrasekaran V. A study on knowledge and practices regarding menstrual hygiene among rural and urban adolescent girls in Udupi Taluk, Manipal, India. Global Journal of Medicine and Public Health. 2013;2(4). Google Scholar $\mid$ Full Text

12. Unicef. Guidance on Menstrual Health and Hygiene. 2019: $1^{\text {st }}$ Eds: 1-92. Full Text

13. Adhikari KB, Dhungel SI, Mandal A. Knowledge and practice regarding menstrual hygiene in rural adolescent girls of Nepal. Kathmandu University Medical Journal. 2007;5(3):382-6. Full Text
14. Sauvey S, Osrin D, Manandhar DS, Costello AM, Wirz S. Prevalence of Childhood and Adolescent Disabilities in Rural Nepal. Indian Pediatr. 2005;I:0-5. Link

15. Yoshimitsu A, Sriareporn P, Upalabut S, Khiaokham P, Matsuo H (2015) Current State of College Women's Coping Behaviors against Peri-menstrual Symptoms and Educational Challenges in Thailand . J Women's Health Care 4: 218. $\underline{\text { CrossRef | Full Text }}$

16. Abdel-Hady El-Gilany, Karima Badawi SE-F. Menstrual Hygiene among Adolescent Schoolgirls in Mansoura, Egypt. Reprod Heath Matters. 2005;8080(5):2 6191-8. Full Text 